\title{
Empirical Analyzing of the Effect of FDI on Emerging Industries in Hebei
}

\author{
Rui $\mathrm{Li}^{1, \mathrm{a}^{*}}$, Shuqiang Ma ${ }^{1, \mathrm{~b}}$ and Jingwei $\mathrm{Lv}^{1, \mathrm{c}}$ \\ ${ }^{1}$ School of Economics and Management, Hebei University of Technology, Tianjin, P.R.China \\ alirui@hebut.edu.cn, ${ }^{b} \mathrm{msq} @$ hebut.edu.cn, ${ }^{\mathrm{C}}$ ljw@hebut.edu.cn
}

Keywords: Foreign Direct Investment (FDI); High-tech zone; Emerging industry; Principal component analysis

\begin{abstract}
Based on data of high-tech zones in Hebei province, by using principal component analysis method, the development of emerging industries in Hebei province is comprehensively measured by 4 indexes, including rate of enterprise industrial output value(y1), total corporate profits(y2), output value of enterprises(y3), and number of enterprises of high-tech zones(y4). Number of foreign investment enterprises(x1), number of $R \& D$ personnel of foreign invested enterprises in high-tech zones(x2), technology expenditures of foreign invested enterprises in high-tech zones(x3), technology activities personnel of foreign investment enterprises in high-tech zones(x4) and technology expenditures of foreign invested enterprises in high-tech zones(x5) are chosen as indicators of foreign direct investment of high-tech development zones to reflect the development of emerging industries in advance. Multicollinearity among original indexes is eliminated; the influence of foreign direct investment to the development of emerging industries in Hebei province is concluded by using principal component regression method. It can be concluded that foreign direct investment not only bring funding for the emerging industries, but also compensate for the industrial development of the "funding gap" and "technology gap" of emerging industries in its development process. Therefore, use of foreign capital and foreign advanced technology to develop new industries of Hebei province is necessary.
\end{abstract}

\section{Introduction}

With the sustained and rapid development of information technology, biotechnology, new materials, and so on, new industries have become the most dynamic source of economic growth.[1] In the near future, as major breakthrough in functional genomics, bioinformatics, new materials science, intelligent integrated manufacturing and other scientific fields, new industries will get into a new round of rapid development period, and will be the great power to the progress of human society[2].

Foreign direct investment in Hebei Province, including U.S. City Group, South Korea's POSCO and Hyundai Heavy Industries, French Louis Dreyfus, Taiwan's Foxconn, Sumitomo and Siemens etc., mainly focus more concentrated in electronics, telecommunications, biotechnology, new energy and other emerging industries, through which had brought large investment projects and high technologies, and had generated a certain amount of capital and technology spillovers for the development of Chinese emerging industries[3]. The question is: What are the implications foreign companies have brought to the development of Hebei emerging industries during foreign entry? This paper will give answer to it through quantitative analysis.

According to the characteristics of new industries and the development of industries in Hebei Province, we select data of National High-tech Development Zones of Shijiazhuang and Baoding as samples to analyze the impact of FDI on the development of new industries. 


\section{Evaluation System Construction}

High-tech Zone is a new growth point of the regional economy. When make quantitative analysis of the impact of foreign direct investment on regional development of emerging industries, the first thing need to do is to select an evaluation system which can reflect the impact. In the existing studies, scholars have selected different indicators to measure the impact, for example, M.Q. Zheng and Li Cai[4] selected proportion of $R \& D$ staff of all workers and proportion of R\&D expenditure of total sales revenue as the indicators of high-tech industry in China; C.Q. Ge and W. Xiong[5] selected labor productivity, export volume for per capita, taxes of industrial output value and profits on one hundred Yuan, corporate average net profit, and corporate average industrial output as indicators in measuring the economic benefits of Chinese high-tech zones; J. Yi, Z. Tang[6] chose average size of enterprises, gross income of technology as indicators in measuring the extent of the development of high-tech zones, and proportion of $\mathrm{R} \& \mathrm{D}$ expenditure to total revenue, proportion of personnel engaged in $\mathrm{R} \& \mathrm{D}$ to persons employed at the end of each year as indicators in technological innovation capability measurement, during the process of evaluating the development of northeast region of the high-tech industry zone; Z.F. Tang and P.L. Gu[7] use high-tech R\&D funding, number of high-tech R\&D personnel, added value of high-tech industry as indicators in reflecting of input level, output level, benefit levels, and potential level of high-tech industries, and established a comprehensive evaluation system of high-tech industry development in advance; J.L. Li and L. Yin[8] made evaluated analysis on 53 national high-tech industrial development zones through integrated the three aspects of economic efficiency, innovation capability and development potential.

Learned from the above scholars and combined with the purpose of this study, we chose rate of enterprise industrial output value(y1), total corporate profits(y2), output value of enterprises(y3), number of enterprises of high-tech zones(y4) to reflect the overall development of High-tech Development Zones in Hebei Province, and took them as indicators of outcome of emerging industries; we also chose number of foreign investment enterprises(x1), number of $R \& D$ personnel of foreign invested enterprises in high-tech zones(x2), technology expenditures of foreign invested enterprises in high-tech zones(x3), technology activities personnel of foreign investment enterprises in high-tech zones(x4) and technology expenditures of foreign invested enterprises in high-tech zones(x5) as indicators of foreign direct investment of high-tech development zones to reflect the development of emerging industries in advance.

\section{Model Establishment}

Principal Component Analysis. Principal Component Analysis is an Exploratory Statistical Analyzing Method, by which dispersed information of a set of variables were concentrated to a few composite indicators (principal components). [9][10]

Data Selection. Index system established in this paper included five independent variable indicators and four dependent variable indicators. According accessibility and availability of data, we selected corresponding data from 2005 to 2014 for analysis. After the standard data processing, Eigen Values and Variance Contribution rate of principal components were calculated. And the number of principal components extracted was determined according to the accumulated variance contribution rate, as shown in Table 1. 
Table 1 Eigen value and variance contributions of principal component

\begin{tabular}{|c|c|c|c|}
\hline $\begin{array}{l}\text { Principal } \\
\text { component }\end{array}$ & Eigen values & $\begin{array}{l}\text { Variance } \\
\text { contribution rate }\end{array}$ & $\begin{array}{l}\text { Accumulated variance } \\
\text { contribution rate }\end{array}$ \\
\hline 1 & 3.096 & 61.917 & 61.917 \\
\hline 2 & 1.614 & 32.284 & 94.201 \\
\hline 3 & 0.199 & 3.988 & 98.189 \\
\hline 4 & 0.056 & 1.120 & 99.310 \\
\hline 5 & 0.035 & 0.690 & 100.000 \\
\hline
\end{tabular}

According to the principal component value calculation equation, values of the first and second main components were calculated, and new sample data was formed. According to the formula $c_{i}=k_{j}=a_{j} x_{j}$, where ${ }^{a_{j}}$ was the Eigen vector components for corresponding Eigen values, the value of ${ }^{a_{j}}$ and corresponding principal component factor score equation were obtained, shown as follows:

$$
\begin{aligned}
& X_{1}^{\prime}=-0.178 x_{1}-0.235 x_{2}+0.020 x_{3}+0.433 x_{4}+0.441 x_{5} \\
& X_{2}^{\prime}=-0.264 x_{1}+0.487 x_{2}+0.382 x_{3}-0.090 x_{4}-0.112 x_{5}
\end{aligned}
$$

It can be seen from the results that the effect of regression fit well. The value of Sig. was 0.001 , which explained that regression equations had passed variance test. Standardized principal component regression equation on the dependent variable (emerging industrial development on high-tech zone) and two principal components has been made and could be expressed as the following formula:

$$
\hat{Y}^{\prime}=-6 E^{-17}+0.731 \hat{X}_{1}^{\prime}+0.654 \hat{X}_{2}^{\prime}
$$

Substituting formula (1) and formula (2) into formula (3), the final principal component regression equation was gotten:

$$
\hat{Y}^{\prime}=-6 E^{-17}-0.30277 x_{1}+0.146713 x_{2}+0.264448 x_{3}+0.257663 x_{4}+0.249123 x_{5}
$$

\section{Regression Analysis}

It can be seen that the regression result and the estimation process were quite satisfactory.The regression equation (1) and (2) showed clearly that technology activities and the development of behavior of foreign direct investment enterprises in High-tech Zone of Hebei province played roles in promoting the development of emerging industries. Numbers of R\&D, expenditures of R\&D, number of technology activities personnel and technology expenditures have brought impacts on the High-tech Development Zones in Hebei, and the respective impact were 0.147,0.264,0.258 and 0.249.

This suggests that foreign research activities, including the technological work, as well as R\&D personnel and capital investment, have become important factors in promoting the development of new industries in Hebei Province. Thus, whether for research and development, or engage in scientific and technological activities, foreign-invested enterprises are two aspects of the development of emerging industries with a catalytic role in funding (expenditure) and technology ( $\&$ T activities in R\&D and personnel).Furthermore, the number of foreign-invested enterprises and the development of high-tech development zones negatively correlated, which showed that not the more foreign enterprises in high- 
tech zones established, the more benefit to the development of high-tech zones would be. This was because more enterprises might form the numerous small-scale enterprises in the industry, were likely to form a vicious competition within the industry, and was not conducive to integration of traditional industries in the industrial structure upgrading and the growth of the emerging industries.

\section{Policy Implications}

From the above analysis, it can be concluded that foreign direct investment not only bring funding for the emerging industries, but also compensate for the industrial development of the "funding gap" and "technology gap" of emerging industries in the process of its development.

Seeing from the current economic strength and technological level of Hebei Province, develop new industries entirely on its own strength in short term is not realistic. Therefore, to develop new industries of Hebei province, use of foreign capital and foreign advanced technology is necessary. Under the background of the international investment market downturn, the government should face difficulties more positively, create better investment environment more actively, expand the open field more widely, increase more measures to promote investment, and strive to absorb more foreign direct investment, in order to inject new vigor and impetus for the development of new industries.

However, under severe conditions of the global economic grim situation, government can not only pursue an increase in the number of investment, while ignoring the quality of foreign investment. Increasing management on foreign investment, and avoiding the adverse effects of high consumption and high pollution which will be brought by blind attract to investment, are guarantees of maintaining healthy development economic, society, and emerging industries.

\section{References}

[1] Xiong Yongqing, Li Shicai. Analysis on the Coupling Process and Function Mechanism of Strategic Emerging Industries and Traditional Industries, Science of Science and Management of S.\&T.. Tianjin, vol. 31, Nov.2010, pp. 84-87.

[2] Shen Junxi. Development Strategy Research from the Perspective of Innovation Modes for Industry-University-Institute Cooperation on the Emerging Industries of Strategic Importance, Science of Science and Management of S.\&T.. Tianjin,vol.33, Feb.2012, pp.37-43.

[3] Yu Xindong, Niu Shaofeng, Yu Yang. Study on background analysis, international comparisons and countermeasures of strategic emerging industries' development, Economic Research, Beijing, vol.16, 2011, pp.2-51.

[4] M.Q. Zheng, L. Cai, M.X. Zhou, Study on the evaluation system construction of High-tech enterprise performance, Science of Science and Management of S.\&T.. Tianjin, vol. 7, 2004, pp. 68-72.

[5] C.Q. Ge, W.Xiong, Comprehensive evaluation on economic dynamics of high-tech zones in China, Science \& Technology Progress and Policy, vol. 4. Wuhan, 2005, pp.63-65.

[6] Z. Tang, J. Yi, Reasearch on development evaluation of High-tech Industrial Development Zones in Northeast of China, Science of Science and Management of S.\&T.. Tianjin, vol. 3, 2004, pp. 94-96.

[7] Z.F. Tang, P.L. Gu, Comprehensive evaluation of the high-tech industrial development. Journal of Xi'an University(Social Science Edition), vol. 3, September 2004, pp. 66-70. 
[8] Hebei Science and Technology Agency, Hebei Science and Technology Statistics Network, http://www.hebsts.org.cn/

[9] Lai Guoyi, Chen Chao. Common Functions and Application examples of SPSS17.0, Publish House of Electronics Industry. Beijing: 2010, pp.316-338.

[10]Deng Weibin, Tang Xingyan, Hu Daquan, Zhou Yumin. SPSS Statistical Analysis Practical Guide, Publish House of Electronics Industry. Beijing: 2012, pp.230-250. 